\title{
Editorial
}

\section{MILEAGE IN RESEARCH COLLABORATION}

For years, the accepted norm was to do your own research and if possible, in your own backyard. Researching in silos was widely practiced but we are certain that it was not as productive as collaboration.

Once researchers begin to see the mileage or benefits of collaborating, there is no turning back. Immediately, researchers recognize and experience the power of minds meeting for a specific scientific purpose. Researchers study not just to test the hypothesis but also to strengthen partnerships and good will to lay the groundwork for more collaboration in the future.

We talked about precision and personalized medicine in the editorial of JMUST's third issue. The patient is at the center of medical diagnosis, treatment, and care. Only with the effective collaboration of clinicians and allied health professionals can the patient's journey purposefully commence and progress.

For JMUST's fourth issue, we take a short step laterally and focus on research collaboration for publication. What mileage or benefits are gained from working on research together? This question is answered by an article in this issue: Challenges in Implementing Research

Initiatives at the Faculty of Medicine and Surgery of the University of Santo Tomas. We learn from this article that research productivity and publication increases with collaboration of the faculty, not just with its medical students and residents, but also with allied health professionals and foreign institutions. There are challenges to operationalizing research, but now we know: collaboration is key!

An example of continuing collaborative research involves the study of X-Linked Dystonia Parkinsonism (XDP) syndrome, which is indigenous to the Philippines. Aside from collaborations among spe- cialists in different hospitals in the Philippines, there are also significant partnerships with the Institute of Neurogenetics, University of Luebeck University Hospital of Schleswig-Holstein, Massachusetts General Hospital and Harvard Medical School. These collaborations have yielded 15 joint publications so far and very recently, identification of extremely promising age modifiers of XDP onset. So, most definitely, strengthened partnerships help increase our research capabilities.

We look forward to seeing more research collaborations and resulting publications in the near future.

We invite our readers to JMUST's six main articles, two case reports, four qualitative studies; one invited review on university research initiative and challenges and three news briefs.

Article submissions have grown steadily since JMUST commenced. We believe that the seeds that we planted to encourage research and publication more than two years ago are beginning to yield more and more original studies.

As always, we thank our indefatigable peer reviewers, associate editors, and staff for their hard work.

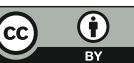

Open Access This article is licensed under a Creative Commons Attribution 4.0 International License, which permits use, sharing, adaptation, distribution and reproduction in any medium or format, as long as you give appropriate credit to the original author(s) and the source, provide a link to the Creative Commons license, and indicate if changes were made. The images or other third party material in this article are included in the article's Creative Commons license, unless indicated otherwise in a credit line to the material. If material is not included in the article's Creative Commons license and your intended use is not permitted by statutory regulation or exceeds the permitted use, you will need to obtain permission directly from the copyright holder. To view a copy of this license, visit http://creativecommons.org/licenses/ by/4.0/. 